\title{
Adherence to Anticholinergic Therapy and Clean Intermittent Self-Catheterization in Patients With Multiple Sclerosis
}

\author{
Damien Motavasseli1 ${ }^{1,2}$, Camille Chesnel ${ }^{1,2}$, Audrey Charlanes ${ }^{1,2}$, Diane Menoux ${ }^{1,2}$, Francis Charoenwong ${ }^{1,2}$, Frédérique Le Breton ${ }^{1,2}$, \\ Gérard Amarenco ${ }^{1,2}$
}

${ }^{1}$ Neuro-urology Department Tenon Hospital, APHP East Hospital Group, Paris, France

${ }^{2}$ GRC-UPMC 01 GREEN, Paris 6, Pierre et Marie Curie University, Paris, France

Purpose: To evaluate adherence to anticholinergic therapy (AT) and clean intermittent self-catheterization (CISC) in patients
with multiple sclerosis (MS) and to identify factors associated with poor adherence.
Methods: This single-center study prospectively included 49 patients suffering from MS who had been prescribed AT and/or
CISC. Adherence was evaluated using a self-report questionnaire. The Expanded Disability Status Scale (EDSS), Patient Global
Impression of Improvement, Mini-Mental State Examination, Urinary Symptom Profile, and Hospital Anxiety and Depres-
sion (HAD) instruments were administered, and the number of daily anticholinergic pills and/or catheterizations was noted.
Whether patients were receiving concomitant intradetrusor botulinum toxin injections was assessed, as were barriers to treat-
ment, side effects, number of spontaneous micturitions, reasons for the prescription, satisfaction, and difficulties.
Results: Only $38 \%$ of patients were adherent to AT. Experiencing side effects was related to nonadherence $(\mathrm{P}=0.02)$. Only
$29 \%$ of patients were adherent to CISC. More intense voiding dysfunction $(\mathrm{P}<0.001)$, a higher frequency of $\mathrm{CISC}(\mathrm{P}=0.03)$,
and a higher EDSS score (P $=0.02)$ were associated with better adherence. Conversely, the HAD score $(\mathrm{P}<0.001)$, depression
(P<0.001), the persistence of spontaneous micturition (P $<0.001)$, a blocking sensation during catheterization $(\mathrm{P}=0.04)$, and
the need to adapt one's posture or gesture to perform catheterization $(\mathrm{P}=0.04)$ were associated with poorer adherence.
Conclusions: Adherence to AT and CISC was poor in patients with MS suffering from bladder dysfunction. Several factors
related to nonadherence were identified in this study, and addressing these factors might help to improve treatment adherence.

Keywords: Multiple sclerosis; Compliance; Intermittent urethral catheterization; Cholinergic antagonists

- Research Ethics: This study was approved by the local ethics committee (Comité de Protection des Personnes Ile de France II: 00001072). Written informed consent was obtained from each participant.

- Conflict of Interest: No potential conflict of interest relevant to this article was reported.

\section{INTRODUCTION}

Treatment adherence is a challenging issue in patients suffering from chronic diseases [1], particularly for patients with significant physical and/or cognitive dysfunctions [2]. This concern is even more important for patients with neurological diseases, such as multiple sclerosis, in which $75 \%$ of patients suffer from bladder dysfunction that is usually characterized by both storage and voiding symptoms [3]. Due to the consequences of urinary dysfunction in terms of medical complications (e.g., renal failure and recurrent urinary tract infections), poor adherence can impact quality of life and lead to increased morbidity and mortality.

Corresponding author: Damien Motavasseli (iD https://orcid.org/0000-0001-8292-8109 Neuro-urology Department Tenon Hospital, APHP East Hospital Group, 4 rue de la Chine, 75020 Paris, France

E-mail: d.motavasseli@gmail.com / Tel: +33-6-80-35-43-45 / Fax: +33-1-56-01-74-81

Submitted: February 17, 2018 / Accepted after revision: May 9, 2018 
Anticholinergic drugs are the most common treatment for overactive bladder [4]. However, a recent review reported that persistence and adherence to anticholinergic therapy were low. This was explained by an unfavorable balance between efficacy and tolerance [5], with widespread side effects due to systemic atropinic effects (constipation, mouth dryness, and cognitive impairment).

While clean intermittent self-catheterization (CISC) is the most effective and safe treatment for bladder voiding dysfunction, it appears that almost half of patients do not carry out CISC as recommended [6].

Despite these facts, no study has been conducted of adherence to these treatments in patients with multiple sclerosis, and more generally, very few such studies have been carried out in patients with neurological diseases.

The aims of this study were to evaluate adherence to anticholinergic therapy and CISC in patients suffering from multiple sclerosis and to identify the factors associated with adherence.

\section{MATERIALS AND METHODS}

A prospective, single-center study was conducted in the Neurourology Department of Tenon Hospital in Paris, France from February to April 2017. All patients who met the following inclusion criteria were consecutively included in the study: being at least 18 years old, having been diagnosed with multiple sclerosis by a neurologist, having a prescription for anticholinergic therapy or CISC, and having been referred to the department for a medical consultation and/or a urodynamic test. Subjects who were specifically referred to learn how to perform CISC, to verify that they had learned to perform CISC, or for a first neuro-urology consultation were not included to rule out risks of bias inherent to the recent initiation of CISC and/or anticholinergic therapy. Among the 49 patients included, 34 had a prescription for anticholinergic drugs and $35 \mathrm{had}$ a prescription for CISC. CISC was prescribed when significant postvoid residual urine was found (over $100 \mathrm{~mL}$ on repeated tests), whereas anticholinergic medication was prescribed to patients with isolated overactive bladder syndrome and/or detrusor hyperactivity on a urodynamic evaluation. Both treatments were prescribed in patients with both storage and voiding symptoms. Written informed consent was obtained from each participant. This study was approved by the local ethics committee (Comité de Protection des Personnes Ile de France II: 00001072).

Treatment adherence was evaluated using self-reported ques- tionnaires. For anticholinergic therapy, we used the Morisky Medical Adherence Scale (MMAS-8) [7], which is a validated tool for evaluating drug adherence. We closely adapted the questions in the MMAS-8 for CISC, and named this adapted formulation the Intermittent-Catheterization Adherence Scale (I-CAS). Patients were considered adherent to anticholinergic therapy if they had an MMAS- 8 score of 8 and adherent to CISC if they had an I-CAS score of 8.

In order to establish the factors that influenced adherence to these treatments, we collected information on patients' functional status (using the Expanded Disability Status Scale [EDSS]), cognitive status (using the Mini-Mental State Examination [MMSE]), the quantitative importance of bladder dysfunction (using the Urinary Symptom Profile [USP] for voiding dysfunction, stress urinary incontinence, and overactive bladder symptoms) [8], the Patient Global Impression of Improvement (PGI-I) [9], the Hospital Anxiety and Depression (HAD) scale, whether the patient was actively receiving botulinum toxin bladder injections, and the patient's perceived barriers to treatment (using a 4-point Likert scale).

For patients undergoing anticholinergic therapy, we also considered the number of daily anticholinergic pills, the presence of side effects (yes/no), and the presence and intensity of xerostomia or constipation (using a 4-point Likert scale).

For patients performing CISC, we also assessed how long it had been since they had started CISC, the number of daily catheterizations, the number of daily spontaneous micturitions, and the reason for the prescription (kidney or bladder morphological abnormalities complete urinary retention, recurrent urinary tract infection, or intradetrusor botulinum toxin injections). The patient's satisfaction with CISC was evaluated using the Intermittent Catheterization Satisfaction Questionnaire [10] and their difficulties were assessed using the Intermittent Catheterization Difficulty Questionnaire (ICDQ) [11].

When patients had been prescribed both anticholinergic therapy and CISC, the corresponding data were collected and analyzed separately. However, for each of these 2 groups, we investigated whether the prescription of one treatment had consequences on adherence to the second treatment (i.e., if concomitant prescription of anticholinergic medication had an effect on CISC adherence and vice versa).

Quantitative data were analyzed using the Student t-test, and qualitative data were analyzed using the chi-square or Fisher test in $\mathrm{R}$ version 3.4.0. 


\section{RESULTS}

\section{Anticholinergic Therapy}

Among the 34 subjects who had a prescription for anticholinergic therapy, only $38 \%$ were adherent according to the MMAS- 8 questionnaire (Fig. 1). Their mean age was 53 years and 59\% were female. Side effects were reported by $71 \%$ of patients. The complete characteristics of the patients prescribed anticholinergic therapy are presented in Table 1 .

The statistical links between anticholinergic therapy adherence and the studied factors are presented in Table 2. Only the presence of side effects was linked to weaker adherence $(\mathrm{P}=0.022)$. Surprisingly, cognitive status (MMSE) and the impression of symptomatic improvement (PGI-I) were not associated with adherence (Table 2).

In Table 3, we present the characteristics of the prescribed treatment in the adherent and the nonadherent groups. Anticholinergic therapy adherence was not related with the mean number of daily anticholinergic pills, a concomitant program of botulinum toxin injection, or a concomitant CISC prescription.

\section{Clean Intermittent Self-Catheterization}

Among the 35 subjects prescribed CISC, only 29\% were adherent (Fig. 1). Their mean age was 50 years, and a majority were female (74\%).

The main reason for which CISC was prescribed was complete urinary retention (66\%), which can be associated with intradetrusor injections of botulinum toxin (63\%). The characteristics of these patients are presented in Table 4.

The factors influencing CISC adherence are reported in Table 5 . Intensity of voiding dysfunction $(\mathrm{P}<0.001)$ and a greater number of daily catheterizations $(\mathrm{P}=0.03)$ were significantly associated with better adherence. The functional status of the

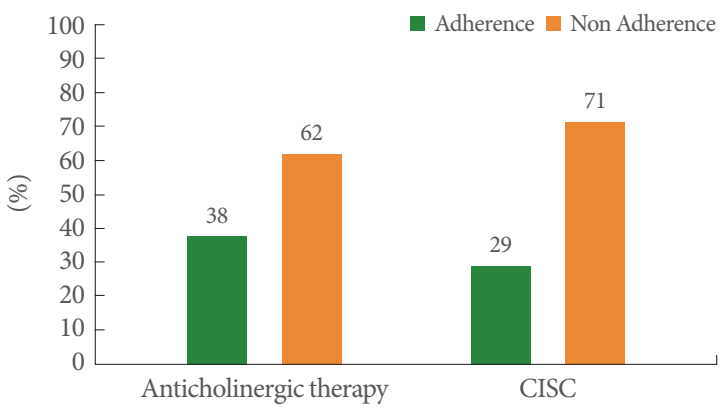

Fig. 1. Anticholinergic therapy and clean intermittent self-catheterization (CISC) adherence proportion.
Table 1. Factors studied in patients with anticholinergic therapy prescriptions $(\mathrm{n}=34)$

\begin{tabular}{|c|c|c|c|}
\hline Variable & Value & Median & Variance \\
\hline Age (yr) & $52.8 \pm 13.9$ & 55.5 & 194.3 \\
\hline PGI-I & $2.4 \pm 1.0$ & 2.0 & 0.9 \\
\hline MMSE & $26.6 \pm 3.7$ & 28.0 & 13.9 \\
\hline USP SUI & $1.2 \pm 2.0$ & 0.0 & 3.8 \\
\hline USP OAB & $6.1 \pm 4.5$ & 5.0 & 20.3 \\
\hline USP VD & $4.3 \pm 3.8$ & 2.0 & 14.1 \\
\hline USP total & $11.5 \pm 6.3$ & 12.0 & 40.3 \\
\hline $\mathrm{HAD}$ & $11.5 \pm 6.5$ & 11.0 & 41.7 \\
\hline Anxiety subscore & $6.7 \pm 3.6$ & 7.0 & 13.3 \\
\hline Depression subscore & $4.9 \pm 3.7$ & 3.0 & 13.6 \\
\hline Number of daily pills $(\mathrm{n}=33)$ & $1.2 \pm 0.6$ & 1.0 & 0.4 \\
\hline $\operatorname{EDSS}(\mathrm{n}=32)$ & $5.1 \pm 1.9$ & 6.0 & 3.6 \\
\hline $\begin{array}{l}\text { Sex }(\%) \\
\text { Female } \\
\text { Male }\end{array}$ & $\begin{array}{l}58.8 \\
41.2\end{array}$ & & \\
\hline $\begin{array}{l}\text { Botulinum toxin injection (\%) } \\
\text { No } \\
\text { Yes }\end{array}$ & $\begin{array}{l}73.5 \\
26.5\end{array}$ & & \\
\hline $\begin{array}{l}\text { MMAS-8 (\%) } \\
\text { Nonadherent } \\
\text { Adherent }\end{array}$ & $\begin{array}{l}61.8 \\
38.2\end{array}$ & & \\
\hline $\begin{array}{l}\text { Side effects } \\
\text { No } \\
\text { Yes }\end{array}$ & $\begin{array}{l}29.4 \\
70.6\end{array}$ & & \\
\hline $\begin{array}{l}\text { Xerostomia (\%) } \\
\text { Not at all } \\
\text { A little } \\
\text { A lot } \\
\text { Enormously }\end{array}$ & $\begin{array}{r}41.2 \\
26.5 \\
23.5 \\
8.8\end{array}$ & & \\
\hline $\begin{array}{l}\text { Constipation (\%) } \\
\text { Not at all } \\
\text { A little } \\
\text { A lot } \\
\text { Enormously }\end{array}$ & $\begin{array}{l}55.9 \\
17.7 \\
14.7 \\
11.8\end{array}$ & & \\
\hline $\begin{array}{l}\text { Barriers (\%) } \\
\text { Not at all } \\
\text { A little } \\
\text { A lot } \\
\text { Enormously }\end{array}$ & $\begin{array}{r}64.7 \\
14.7 \\
11.8 \\
8.8\end{array}$ & & \\
\hline $\begin{array}{l}\text { CISC (\%) } \\
\text { No } \\
\text { Yes }\end{array}$ & $\begin{array}{l}41.2 \\
58.8\end{array}$ & & \\
\hline
\end{tabular}

Values are presented as mean \pm standard deviation unless otherwise indicated.

PGI-I, Patient Global Impression of Improvement; MMSE, Mini-Mental State Examination; USP, Urinary Symptom Profile; SUI, stress urinary incontinence; $\mathrm{OAB}$, overactive bladder; $\mathrm{VD}$, voiding dysfunction; HAD, Hospital Anxiety and Depression scale; EDSS, Expended Disability Status Scale; MMAS-8, Morisky Medical Adherence Scale (8-items); CISC, clean intermittent self-catheterization. 
Table 2. Associations between anticholinergic therapy adherence (MMAS-8) and the studied factors

\begin{tabular}{lccc}
\hline Evaluated factor & P-value & $95 \%$ CI & OR \\
\hline Age & $0.810^{\mathrm{a})}$ & -8.03 to 10.20 & - \\
PGI-I & $0.824^{\mathrm{a})}$ & -0.59 to 0.74 & - \\
MMSE & $0.766^{\mathrm{a})}$ & -2.88 to 2.14 & - \\
USP SUI & $0.060^{\mathrm{a})}$ & -0.05 to 2.27 & - \\
USP OAB & $0.151^{\mathrm{a})}$ & -0.79 to 4.91 & - \\
USP VD & $0.562^{\mathrm{a})}$ & -3.69 to 2.05 & - \\
USP total & $0.257^{\mathrm{a})}$ & -1.80 to 6.50 & - \\
HAD & $0.056^{\mathrm{a})}$ & -0.11 to 7.80 & - \\
Anxiety sub-score & $0.066^{\mathrm{a})}$ & -0.14 to 4.33 & - \\
Depression sub-score & $0.151^{\mathrm{a})}$ & -0.68 to 4.19 & - \\
Number of daily pills & $0.618^{\mathrm{a})}$ & -0.29 to 0.49 & - \\
EDSS & $0.704^{\mathrm{a})}$ & -1.20 to 1.75 & - \\
Sex & $0.800^{\mathrm{b})}$ & - & - \\
CISC & $0.643^{\mathrm{b})}$ & - & - \\
Botulinum toxin injection & $1.000^{\mathrm{c})}$ & $0.10-4.62$ & 0.76 \\
Side effects & $0.022^{\mathrm{c})}$ & $0.02-0.93$ & 0.15 \\
Xerostomia & $0.222^{\mathrm{c})}$ & - & - \\
Constipation & $0.689^{\mathrm{c})}$ & - & - \\
Barriers & $0.058^{\mathrm{c})}$ & - & - \\
\hline
\end{tabular}

MMAS-8, Morisky Medical Adherence Scale (8-items); CI, confidence interval; OR, odds ratio; PGI-I, Patient Global Impression of Improvement; MMSE, Mini-Mental State Examination; USP, Urinary Symptom Profile; SUI, stress urinary incontinence; $\mathrm{OAB}$, overactive bladder; VD, voiding dysfunction; HAD, Hospital Anxiety and Depression scale; EDSS, Expended Disability Status Scale; CISC, clean intermittent selfcatheterization.

${ }^{\star}$ Significant difference ${ }^{\text {a) }} t$-test. ${ }^{\text {b) }}$ Chi-square test. ${ }^{c)}$ Fisher exact test.

adherent patients was better (mean EDSS score, 5.95; standard deviation $[\mathrm{SD}], 1.14)$ than that of the nonadherent patients (mean EDSS score, 4.83; SD, 1.39). Higher EDSS scores were therefore associated with better adherence to CISC $(\mathrm{P}=0.02)$.

A greater number of daily spontaneous micturition events $(\mathrm{P}<0.001)$, a blocking sensation when introducing the catheter, and the need to change position or to insert fingers to perform the catheterization (items 2, 3, 4, and 7 of the ICDQ score) were significantly related with poorer adherence, as were higher HAD scores $(\mathrm{P}<0.001)$ and depression subscores $(\mathrm{P}<0.001)$.

Except the number of daily catheterizations, there were no significant differences between the nonadherent and the adherent groups in terms of treatment characteristics (the duration of CISC and the rates of actively receiving botulinum toxin injec-
Table 3. Treatment characteristics and reasons for prescription in the nonadherent and the adherent groups

\begin{tabular}{|c|c|c|}
\hline Variable & Value & $\mathrm{P}$-value \\
\hline \multicolumn{3}{|l|}{ Anticholinergic therapy } \\
\hline No. of daily pills & & $0.618^{\mathrm{a})}$ \\
\hline Nonadherent $(\mathrm{n}=20)$ & $1.25 \pm 0.72$ & \\
\hline Adherent $(n=13)$ & $1.15 \pm 0.38$ & \\
\hline \multicolumn{2}{|c|}{ Concomitant botulinum toxin injection (\%) } & $1.000^{\mathrm{b})}$ \\
\hline \multicolumn{3}{|l|}{ Nonadherent } \\
\hline No & 71 & \\
\hline \multirow{2}{*}{\multicolumn{3}{|c|}{ Adherent }} \\
\hline & & \\
\hline No & 77 & \\
\hline Yes & 23 & \\
\hline \multicolumn{2}{|l|}{ Concomitant CISC (\%) } & $0.643^{c)}$ \\
\hline \multicolumn{3}{|l|}{ Nonadherent } \\
\hline No & 38 & \\
\hline Yes & 62 & \\
\hline \multicolumn{3}{|l|}{ Adherent } \\
\hline No & 46 & \\
\hline Yes & 54 & \\
\hline \multicolumn{3}{|l|}{ Clean intermittent self-catheterization } \\
\hline CISC duration (mo) & & $0.079^{\mathrm{a})}$ \\
\hline Nonadherent $(\mathrm{n}=24)$ & $52.5 \pm 48.06$ & \\
\hline Adherent $(\mathrm{n}=9)$ & $100.7 \pm 68.7$ & \\
\hline \multicolumn{2}{|l|}{ No. of daily CISC ${ }^{\star}$} & $0.031^{\mathrm{a})}$ \\
\hline Nonadherent $(\mathrm{n}=25)$ & $5.1 \pm 1.6$ & \\
\hline Adherent $(\mathrm{n}=10)$ & $7.3 \pm 2.7$ & \\
\hline \multicolumn{2}{|c|}{ Concomitant botulinum toxin injection (\%) } & $0.055^{\mathrm{b})}$ \\
\hline \multicolumn{3}{|l|}{ Nonadherent } \\
\hline No & 48 & \\
\hline Yes & 52 & \\
\hline \multicolumn{3}{|l|}{ Adherent } \\
\hline No & 10 & \\
\hline \multirow{2}{*}{\multicolumn{2}{|c|}{ Concomitant anticholinergic therapy (\%) }} & \\
\hline & & $1.000^{\mathrm{b})}$ \\
\hline \multicolumn{3}{|l|}{ Nonadherent } \\
\hline No & 44 & \\
\hline Yes & 56 & \\
\hline \multicolumn{3}{|l|}{ Adherent } \\
\hline No & 40 & \\
\hline \multirow{2}{*}{\multicolumn{2}{|c|}{ Cause: repeated UTI (\%) }} & \\
\hline & & $0.391^{\mathrm{b})}$ \\
\hline \multicolumn{3}{|l|}{ Nonadherent } \\
\hline No & 72 & \\
\hline Yes & 28 & \\
\hline Adherent & & \\
\hline No & 90 & \\
\hline Yes & 10 & \\
\hline Cause: complete urinary retention (\%) & & $0.113^{\mathrm{b})}$ \\
\hline Nonadherent & & \\
\hline No & 44 & \\
\hline Yes & 56 & \\
\hline Adherent & & \\
\hline No & 10 & \\
\hline Yes & 90 & \\
\hline Cause: morphological abnormality (\%) & & $1.000^{\mathrm{b})}$ \\
\hline Nonadherent & & \\
\hline No & 96 & \\
\hline Yes & 4 & \\
\hline Adherent & & \\
\hline No & 100 & \\
\hline Yes & 0 & \\
\hline
\end{tabular}

Values are presented as mean \pm standard deviation unless otherwise indicated.

CISC, clean intermittent self-catheterization; UTI, urinary tract infection; SD, standard deviation.

${ }^{*}$ Significant difference. ${ }^{\mathrm{a}} t$-test. ${ }^{\mathrm{b})}$ Fisher exact test. ${ }^{\mathrm{c}}$ Chi-square test. 
Table 4. Factors studied in patients with CISC prescriptions $(\mathrm{n}=35)$

\begin{tabular}{|c|c|c|c|}
\hline Variable & Value & Median & Variance \\
\hline Age & $50.1 \pm 12.1$ & 51.0 & 146.1 \\
\hline PGI-I & $1.9 \pm 0.7$ & 2.0 & 0.5 \\
\hline MMSE & $27.4 \pm 2.5$ & 28.0 & 6.1 \\
\hline USP SUI & $0.6 \pm 1.5$ & 0.0 & 2.2 \\
\hline USP OAB & $4.1 \pm 3.4$ & 3.0 & 11.4 \\
\hline USP VD & $6.9 \pm 3.2$ & 9.0 & 10.5 \\
\hline USP total & $11.7 \pm 5.6$ & 12.0 & 31.2 \\
\hline HAD & $10.6 \pm 6.3$ & 10.0 & 39.4 \\
\hline Anxiety sub-score & $6.2 \pm 3.6$ & 5.0 & 13.3 \\
\hline Depression sub-score & $4.5 \pm 3.6$ & 3.0 & 13.0 \\
\hline CISC duration $(\mathrm{mo})(\mathrm{n}=33)$ & $65.6 \pm 57.6$ & 42.0 & $3,315.4$ \\
\hline Number of daily CISC & $5.7 \pm 2.2$ & 5.0 & 4.8 \\
\hline Spontaneous micturitions/day & $1.5 \pm 1.9$ & 0.0 & 3.6 \\
\hline $\mathrm{InCaSaQ}(\mathrm{n}=33)$ & $5.9 \pm 4.1$ & 8.0 & 16.8 \\
\hline ICDQ total $(\mathrm{n}=32)$ & $4.8 \pm 5.8$ & 2.0 & 33.7 \\
\hline $\operatorname{EDSS}(\mathrm{n}=33)$ & $5.2 \pm 1.4$ & 5.5 & 2.0 \\
\hline \multicolumn{4}{|l|}{$\operatorname{Sex}(\%)$} \\
\hline Female & 74.3 & & \\
\hline Male & 25.7 & & \\
\hline \multicolumn{4}{|l|}{ Botulinum toxin injection (\%) } \\
\hline Yes & 62.9 & & \\
\hline No & 37.1 & & \\
\hline \multicolumn{4}{|l|}{ Anticholinergic therapy (\%) } \\
\hline Yes & 57.1 & & \\
\hline No & 42.9 & & \\
\hline \multicolumn{4}{|l|}{ I-CAS (\%) } \\
\hline Nonadherent & 71.4 & & \\
\hline Adherent & 28.6 & & \\
\hline \multicolumn{4}{|l|}{ Barriers (\%) } \\
\hline Not at all & 42.9 & & \\
\hline A little & 31.4 & & \\
\hline A lot & 22.9 & & \\
\hline Enormously & 2.9 & & \\
\hline \multicolumn{4}{|l|}{ Repeated UTI (\%) } \\
\hline No & 77.1 & & \\
\hline Yes & 22.9 & & \\
\hline \multicolumn{4}{|l|}{ Complete urinary retention (\%) } \\
\hline No & 34.3 & & \\
\hline Yes & 65.7 & & \\
\hline \multicolumn{4}{|l|}{ Morphological abnormality (\%) } \\
\hline No & 97.1 & & \\
\hline Yes & 2.9 & & \\
\hline
\end{tabular}

Values are presented as mean \pm standard deviation unless otherwise indicated.

CISC, clean intermittent self-catheterization; SD, standard deviation; PGI-I, Patient Global Impression of Improvement; MMSE, Mini-Mental State Examination; USP, Urinary Symptom Profile; SUI, stress urinary incontinence; $\mathrm{OAB}$, overactive bladder; $\mathrm{VD}$, voiding dysfunction; HAD, Hospital Anxiety and Depression scale; InCaSaQ, Intermittent Catheterization Satisfaction Questionnaire; ICDQ, Intermittent Catheterization Difficulty Questionnaire; EDSS, Expended Disability Status Scale; I-CAS, Intermittent-Catheterization Scale; UTI, urinary tract infection.
Table 5. Associations between CISC adherence (I-CAS) and the studied factors

\begin{tabular}{|c|c|c|c|}
\hline Evaluated factor & $\mathrm{P}$-value & $95 \% \mathrm{CI}$ & OR \\
\hline Age & $0.359^{\mathrm{a})}$ & -15.48 to 6.00 & \\
\hline PGI-I & $0.535^{\mathrm{a})}$ & -0.48 to 0.88 & \\
\hline MMS & $0.966^{\mathrm{a})}$ & -1.91 to 1.99 & \\
\hline USP SUI & $0.868^{\mathrm{a})}$ & -1.36 to 1.16 & \\
\hline USP OAB & $0.881^{\text {a) }}$ & -2.60 to 3.00 & \\
\hline USP VD* & $<0.001^{\mathrm{a})}$ & -4.41 to -1.51 & \\
\hline USP total & $0.116^{\mathrm{a})}$ & -6.47 to 0.75 & \\
\hline $\mathrm{HAD}^{*}$ & $<0.001^{\mathrm{a})}$ & 2.82 to 9.30 & \\
\hline Anxiety subscore & $0.052^{\mathrm{a})}$ & -0.02 to 4.42 & \\
\hline Depression subscore ${ }^{*}$ & $<0.001^{\mathrm{a})}$ & 2.21 to 5.51 & \\
\hline CISC duration (months) & $0.079^{\mathrm{a})}$ & -102.97 to 6.64 & \\
\hline Number of daily CISC ${ }^{\star}$ & $0.031^{\text {a) }}$ & -4.19 to -0.24 & \\
\hline Spontaneous micturition/day* & $<0.001^{\mathrm{a})}$ & 1.05 to 2.75 & \\
\hline InCaSaQ & $0.253^{\mathrm{a})}$ & -1.52 to 5.37 & \\
\hline EDSS $^{*}$ & $0.024^{\mathrm{a})}$ & -2.09 to -0.16 & \\
\hline Sex & $0.235^{\mathrm{b})}$ & $0.42-208.24$ & 4.09 \\
\hline Botulinum toxin injection & $0.055^{\mathrm{b})}$ & $0.86-392.98$ & 7.88 \\
\hline Anticholinergic therapy & $1.000^{\mathrm{b})}$ & $0.21-7.15$ & 1.17 \\
\hline Repeated UTI & $0.391^{\mathrm{b})}$ & $0.01-2.92$ & 0.29 \\
\hline Complete urinary retention & $0.113^{\mathrm{b})}$ & $0.73-336.95$ & 6.74 \\
\hline Morphological abnormality & $1.000^{\mathrm{b})}$ & $0-97.35$ & 0.00 \\
\hline ICDQ total & $0.058^{\mathrm{c})}$ & -0.12 to 7.34 & \\
\hline Item $1 \mathrm{i}$ & $0.669^{c)}$ & -0.4 to 0.61 & \\
\hline Item if & $0.357^{\mathrm{c})}$ & -0.15 to 0.41 & \\
\hline Item $2 \mathrm{i}^{*}$ & $<0.001^{\mathrm{c})}$ & 0.39 to 1.09 & \\
\hline Item $2 \mathrm{f}^{*}$ & $<0.001^{\mathrm{c})}$ & 0.34 to 1.03 & \\
\hline Item $3 \mathrm{i}^{*}$ & $0.031^{c}$ & 0.03 to 0.58 & \\
\hline Item $3 \mathrm{f}$ & $0.057^{\mathrm{c})}$ & -0.01 to 0.46 & \\
\hline Item $4 \mathrm{i}$ & $0.057^{\mathrm{c})}$ & -0.01 to 0.44 & \\
\hline Item $4 \mathrm{f}^{*}$ & $0.042^{c)}$ & 0.01 to 0.36 & \\
\hline Item $5 \mathrm{i}$ & $0.083^{c)}$ & -0.02 to 0.28 & \\
\hline Item $5 \mathrm{f}$ & $0.083^{c)}$ & -0.02 to 0.29 & \\
\hline Item $6 \mathrm{i}$ & $0.162^{\mathrm{c})}$ & -0.04 to 0.21 & \\
\hline Item $6 f$ & $0.329^{c)}$ & -0.05 to 0.14 & \\
\hline Item $7 \mathrm{i}$ & $0.083^{c)}$ & -0.02 to 0.29 & \\
\hline Item $7 f^{*}$ & $0.042^{c)}$ & 0.01 to 0.36 & \\
\hline Item $8 \mathrm{i}$ & $0.110^{c)}$ & -0.08 to 0.71 & \\
\hline Item $8 \mathrm{f}$ & $0.110^{c)}$ & -0.07 to 0.61 & \\
\hline Item $9 \mathrm{i}$ & $0.613^{\mathrm{c})}$ & -0.29 to 0.18 & \\
\hline Item $9 \mathrm{f}$ & $0.940^{c)}$ & -0.26 to 0.24 & \\
\hline Item $10 \mathrm{i}$ & $0.658^{c)}$ & -0.39 to 0.6 & \\
\hline Item $10 \mathrm{f}$ & $0.227^{c)}$ & -0.11 to 0.46 & \\
\hline Item $11 \mathrm{i}$ & $0.422^{\mathrm{c})}$ & -0.94 to 0.43 & \\
\hline Item $11 \mathrm{f}$ & $0.628^{\mathrm{c})}$ & -0.29 to 0.18 & \\
\hline Item $12 \mathrm{i}$ & $0.663^{c)}$ & -0.89 to 0.58 & \\
\hline Item $12 \mathrm{f}$ & $0.878^{\mathrm{c})}$ & -0.52 to 0.45 & \\
\hline Item $13 \mathrm{i}$ & $0.664^{c)}$ & -0.27 to 0.42 & \\
\hline Item $13 \mathrm{f}$ & $0.940^{c)}$ & -0.26 to 0.24 & \\
\hline
\end{tabular}

CISC, clean intermittent self-catheterization; I-CAS, IntermittentCatheterization Scale; CI, confidence interval; OR, odds ratio; PGI-I, Patient Global Impression of Improvement; MMSE, Mini-Mental State Examination; USP, Urinary Symptom Profile; SUI, stress urinary incontinence; $\mathrm{OAB}$, overactive bladder; $\mathrm{VD}$, voiding dysfunction; $\mathrm{HAD}$, Hospital Anxiety and Depression scale; InCaSaQ, Intermittent Catheterization Satisfaction Questionnaire; EDSS, Expended Disability Status Scale; UTI, urinary tract infection; ICDQ: Intermittent Catheterization Difficulty Questionnaire.

${ }^{\star}$ Significant difference. ${ }^{\mathrm{a}} t$-test. ${ }^{\mathrm{b})} \mathrm{Chi}$-square test. ${ }^{\mathrm{c})}$ Fisher exact test. 
tions and concomitant anticholinergic intake were comparable between the groups) or in terms of the reasons for CISC prescription (the proportions of repeated urinary tract infections, complete urinary retention, and morphological complications were essentially the same). These results are presented in Table 3.

\section{DISCUSSION}

\section{Terminology}

Whether a patient actually takes the treatment that has been prescribed is an ancient problem, already identified by physicians in classical Greece and Rome. This is a complex concept for which we often use a poorly defined vocabulary [12]. Adherence is a generic term that reflects the patient's comprehension of the prescribed treatment and agreement to take it. However, adherence can only be quantified using the concepts of compliance and persistence. Compliance measures the degree to which the patient's behavior corresponds with the prescriber's recommendation. Persistence introduces the notion of temporality by assessing the duration of the treatment. Concordance designates the degree of agreement between the prescriber and the patient regarding the patient's treatment. Lastly, acceptance is related to how the patient experiences the riskbenefit balance of pathology and treatment. Thus, concordance and acceptance determine the patient's behavior.

\section{Factors Associated With Adherence in the Literature}

Several studies have focused on patients' adherence to treatment, aiming to evaluate it and to identify factors that could influence it.

Satisfaction, efficiency, side effects, and the presence of comorbidities influence adherence $[13,14]$. Some other obstacles include physical or cognitive deficiencies and the lack of social support [13]. In elderly patients, help at home, the number of daily pills to take, self-sufficiency, and engaging in physical activities are other features associated with treatment adherence [2].

Regarding multiple sclerosis more specifically, a few studies have investigated factors influencing adherence to immunomodulatory drugs. An analysis of emotional status, personality, and cognition showed that mood disorders, anxiety, memory impairment, and comprehension difficulties were associated with poorer adherence [15]. In such patients, communication with the medical team seemed to be crucial for improving the patients' knowledge about the medication and for promoting further adherence [16].

\section{Adherence to Anticholinergic Therapy}

Our results indicated that only side effects were linked to adherence to anticholinergic therapy. Indeed, this family of medications is well known to cause constipation, xerostomia, urinary retention, and cognitive alterations. Adherence to anticholinergic therapy is even lower than to treatments that do not lead to any immediate symptomatic improvements in patients (e.g., oral antidiabetic agents, angiotensin receptor antagonists, statins, bisphosphonates, and prostaglandin) [17]. Despite new generations of anticholinergic medications that are more efficient and better tolerated [18], adherence remains problematic [4], especially since anticholinergic therapy is often prescribed to patients with multiple sclerosis to improve their quality of life, not always in order to reduce renal risk factors. This gives the patient the opportunity to make a real judgment regarding the efficacy of anticholinergic therapy in terms of the balance between symptom relief and side effects.

In this study, we chose not to consider the period, type, or dose of anticholinergic medication. Since patients were followed by neuro-urology experts in a specialized department, we believe that their prescriptions were adjusted to the most favorable balance between efficacity and tolerance. Since several antimuscarinic compounds (e.g., oxybutynin, solifenacin, trospium chloride, and fesoterodine) had a reasonably even distribution in our study population, it would have been necessary to include a very large number of patients in the study to distinguish among these compounds, which was difficult to achieve in this prospective study. Furthermore, this was not our specific goal, as we aimed to focus on a more global evaluation of adherence to anticholinergic therapy and to CISC. However, we thought that it was imperative to evaluate the number of daily pills that patients were required to take, which was not correlated with adherence in this study (Table 2), in contrast with the overall literature on adherence in elderly patients [2].

The implications of poor adherence are numerous. It can lead to increased morbidity, mortality, and more medical visits and hospitalizations [19]. In elderly patients, poor adherence to anticholinergic therapy directly increases health care utilization (i.e., the use of health services and medicines) [20].

\section{Adherence to CISC}

Numerous factors determine adherence to CISC. It is a technical procedure about which patients may have misconceptions and feelings of shame and/or fear, with significant effects on their willingness to perform CISC [21]. Nonetheless, when cor- 
rectly performed, it broadly improves quality of life and is not experienced as a burden [22]. To promote further adherence, it is essential to reassure patients by anticipating the difficulties they may encounter during multiple learning sessions with the help of an experienced practitioner and the support of a welltrained team [23]. The technical feasibility of CISC can be quickly evaluated by a simple tool known as the pencil-and-paper test [24]. However, no study has established the efficacy of a therapeutic educational program on acceptance and compliance with CISC in this population.

It seems that the progression of multiple sclerosis and cognitive decline are not barriers to performing CISC [25]. This was also demonstrated in our study, as physical and cognitive deficiencies (evaluated by the EDSS score and MMSE) were not associated with adherence to CISC (or with anticholinergic therapy). In contrast, higher EDSS scores were associated with better CISC adherence. Since the EDSS score calculation takes into account the degree of bladder dysfunction, which is higher in patients who must practice CISC, this was to be expected. As shown in the literature on immunomodulatory medications, mood disorders seem to affect adherence to CISC, but more surprisingly, satisfaction with CISC was not linked to adherence.

Anticholinergic medication intake and intradetrusor injections of botulinum toxin should also have affected the prescription of CISC, because those treatments increase postvoid residual volume, making CISC necessary. When their therapeutic effect fades, CISC is no longer necessarily required. In our population, many of the patients were actively following a botulinum toxin injection program (62.9\%; Table 4$)$, which made complete urinary retention the main reason for the prescription of CISC (66\%). Of the patients who were adherent to CISC, $90 \%$ were following such a program, in contrast to only $52 \%$ of patients who were not adherent (Table 3). Therefore, the link between adherence to CISC and botulinum toxin injections was almost statistically significant $(\mathrm{P}=0.055)$ (Table 5$)$. In contrast, anticholinergic medication intake was not linked to CISC adherence at all (Table 5).

\section{Study Limitations}

In multiple sclerosis, patients with bladder dysfunction suffer from both storage and voiding symptoms, which makes their medical care more difficult for practitioners. Therefore, accurately prescribing anticholinergic medications or CISC can be challenging. This is a crucial point, since adherence is most likely affected by the degree to which patients perceive their treatment to be appropriate for their symptoms. Our results reflect this possibility, as a greater intensity of voiding dysfunction expressed by patients (through the USP for voiding dysfunction) was linked with better CISC adherence (Table 5). Since our study took place in a specialized neuro-urology center where patients were evaluated by expert physicians, we considered their prescriptions to have been appropriate for optimal treatment effects. Moreover, the treatments were prescribed before this study took place, excluding patient selection bias.

Another limitation is that our sample did not include patients whose functional status (as determined by the EDSS score) was too deteriorated for them to successfully perform CISC. In addition, some of them had already had received specific consultation sessions to assess CISC performance and to detect any technical or psychological difficulties that they may have had. This suggests that the CISC adherence level, which was already mediocre, may have been overestimated in our study. The statistical power for identifying factors influencing adherence might also have been reduced by these issues.

The number of patients included in this prospective study was also relatively small (34 patients in the analysis of anticholinergic therapy and 35 patients for CISC). However, the statistical tests that we used are suited to allow statistical significance to be proven in populations containing over 30 subjects.

Furthermore, the I-CAS score, which was used to evaluate CISC adherence, has not been rigorously validated, since we adapted the items of MMAS- 8 to fit the specific aspects of CISC. Since there is no validated scoring system for this procedure, the use of this instrument, which was developed in our department using the same framework as the MMAS-8, with only adjustments for the technical aspects of CISC, seems to be legitimate.

In conclusion, adherence to anticholinergic treatment and to CISC was poor among patients suffering from multiple sclerosis (38\% and $29 \%$, respectively). Several factors related to nonadherence were identified in this study, and addressing these factors might help to improve treatment adherence.

\section{ACKNOWLEDGEMENTS}

The authors would like to gratefully acknowledge the contributions of Charlotte Gil and Samer Ismael in the writing of this paper. 


\section{AUTHOR CONTRIBUTION STATEMENT}

- Full access to all the data in the study and takes responsibility for the integrity of the data and the accuracy of the data analysis: $D$. Motavasseli, C. Chesnel, A. Charlanes, D. Menoux, F. Charoenwong, F. Le Breton, G. Amarenco

-Study concept and design: D. Motavasseli, C. Chesnel, A. Charlanes, D. Menoux, F. Charoenwong, F. Le Breton, G. Amarenco

- Acquisition of data: D. Motavasseli, C. Chesnel, A. Charlanes, D. Menoux, F. Charoenwong, F. Le Breton, G. Amarenco

- Analysis and interpretation of data: D. Motavasseli, G. Amarenco

- Drafting of the manuscript: D. Motavasseli, G. Amarenco

- Critical revision of the manuscript for important intellectual content: D. Motavasseli, C. Chesnel, A. Charlanes, D. Menoux, F. Charoenwong, F. Le Breton, G. Amarenco

-Statistical analysis: D. Motavasseli, C. Chesnel, G. Amarenco - Obtained funding: No funding

- Administrative, technical, or material support: D. Motavasseli - Study supervision: D. Motavasseli, C. Chesnel, A. Charlanes, D. Menoux, F. Charoenwong, F. Le Breton, G. Amarenco

\section{REFERENCES}

1. Jackevicius CA, Mamdani M, Tu JV. Adherence with statin therapy in elderly patients with and without acute coronary syndromes. JAMA 2002;288:462-7.

2. Monane M, Bohn RL, Gurwitz JH, Glynn RJ, Levin R, Avorn J. The effects of initial drug choice and comorbidity on antihypertensive therapy compliance: results from a population-based study in the elderly. Am J Hypertens 1997;10(7 Pt 1):697-704.

3. DasGupta R, Fowler CJ. Bladder, bowel and sexual dysfunction in multiple sclerosis: management strategies. Drugs 2003;63:153-66.

4. Gomelsky A, Dmochowski RR. Update on the management of overactive bladder: patient considerations and adherence. Open Access J Urol 2010;3:7-17.

5. Sexton CC, Notte SM, Maroulis C, Dmochowski RR, Cardozo L, Subramanian D, et al. Persistence and adherence in the treatment of overactive bladder syndrome with anticholinergic therapy: a systematic review of the literature. Int J Clin Pract 2011;65:567-85.

6. Bolinger R, Engberg S. Barriers, complications, adherence, and self-reported quality of life for people using clean intermittent catheterization. J Wound Ostomy Continence Nurs 2013;40:83-9.

7. Morisky DE, Ang A, Krousel-Wood M, Ward HJ. Predictive validity of a medication adherence measure in an outpatient setting. J
Clin Hypertens (Greenwich) 2008;10:348-54.

8. Abrams P, Cardozo L, Fall M, Griffiths D, Rosier P, Ulmsten U, et al. The standardisation of terminology of lower urinary tract function: report from the Standardisation Sub-committee of the International Continence Society. Neurourol Urodyn 2002;21:167-78.

9. Yalcin I, Bump RC. Validation of two global impression questionnaires for incontinence. Am J Obstet Gynecol 2003;189:98-101.

10. Guinet-Lacoste A, Jousse M, Verollet D, Sheikh Ismael S, Le Breton F, Tan E, et al. Validation of the InCaSaQ, a new tool for the evaluation of patient satisfaction with clean intermittent self-catheterization. Ann Phys Rehabil Med 2014;57:159-68.

11. Guinet-Lacoste A, Jousse M, Tan E, Caillebot M, Le Breton F, Amarenco G. Intermittent catheterization difficulty questionnaire (ICDQ): a new tool for the evaluation of patient difficulties with clean intermittent self-catheterization. Neurourol Urodyn 2016;35: 85-9.

12. Vrijens B, Urquhart J. Patient adherence to prescribed antimicrobial drug dosing regimens. J Antimicrob Chemother 2005;55:616-27.

13. Gellad WF, Grenard JL, Marcum ZA. A systematic review of barriers to medication adherence in the elderly: looking beyond cost and regimen complexity. Am J Geriatr Pharmacother 2011;9:1123.

14. Barbosa CD, Balp MM, Kulich K, Germain N, Rofail D. A literature review to explore the link between treatment satisfaction and adherence, compliance, and persistence. Patient Prefer Adherence 2012;6:39-48.

15. Bruce JM, Hancock LM, Arnett P, Lynch S. Treatment adherence in multiple sclerosis: association with emotional status, personality, and cognition. J Behav Med 2010;33:219-27.

16. Costello K, Kennedy P, Scanzillo J. Recognizing nonadherence in patients with multiple sclerosis and maintaining treatment adherence in the long term. Medscape J Med 2008;10:225.

17. Fed Pract 2014. Adherence issues with overactive bladder treatment [Internet]. Parsippany (NJ): Frontline Medical Communications Inc.; c2018 [cited 2016 Nov 16]. Available from: http://www. mdedge.com/fedprac/article/80868/nephrology/adherence-issuesoveractive-bladder-treatment.

18. Appell RA. The newer antimuscarinic drugs: bladder control with less dry mouth. Cleve Clin J Med 2002;69:761, 765-6, 768-9.

19. Granger BB, Swedberg K, Ekman I, Granger CB, Olofsson B, McMurray JJ, et al. Adherence to candesartan and placebo and outcomes in chronic heart failure in the CHARM programme: doubleblind, randomised, controlled clinical trial. Lancet 2005;366:200511.

20. Balkrishnan R, Bhosle MJ, Camacho FT, Anderson RT. Predictors 
of medication adherence and associated health care costs in an older population with overactive bladder syndrome: a longitudinal cohort study. J Urol 2006;175(3 Pt 1):1067-71.

21. van Achterberg T, Holleman G, Cobussen-Boekhorst H, Arts R, Heesakkers J. Adherence to clean intermittent self-catheterization procedures: determinants explored. J Clin Nurs 2008;17:394-402.

22. Kessler TM, Ryu G, Burkhard FC. Clean intermittent self-catheterization: a burden for the patient? Neurourol Urodyn 2009;28:18-21.

23. Seth JH, Haslam C, Panicker JN. Ensuring patient adherence to clean intermittent self-catheterization. Patient Prefer Adherence
2014;8:191-8.

24. Amarenco G, Guinet A, Jousse M, Verollet D, Ismael SS. Pencil and paper test: a new tool to predict the ability of neurological patients to practice clean intermittent self-catheterization. J Urol 2011;185:57882.

25. Vahter L, Zopp I, Kreegipuu M, Kool P, Talvik T, Gross-Paju K. Clean intermittent self-catheterization in persons with multiple sclerosis: the influence of cognitive dysfunction. Mult Scler 2009; 15:379-84. 